\title{
MORPHOLOGY AND DISTRIBUTION PATTERNS OF GALANIN IMMUNOREACTIVE AXONS IN THE RAT BASAL FOREBRAIN COMPARISON WITH THE DISTRIBUTION PATTERNS OF GAD IMMUNOREACTIVE AXONS
}

\author{
Andreas SCHOBER ${ }^{1}$, Kurt BRAUER ${ }^{2}$, Olle JOHANSSON ${ }^{3}$, \\ HANS LUPPA $^{4}$, AND WILFRIEd SCHOBER ${ }^{2}$ \\ Academy of Sciences ${ }^{1}$, Institute for Neurobiologie and Brain Research, Brennecke str. 6, \\ O-3090 Magdeburg, FRG, Leipzig University², Paul Flechsig Institute for \\ Brain Research, Emilienstr. 14, O-7010 Leipzig, FRG, Karolinska \\ Institute ${ }^{3}$, Department of Histology and Neurobiology, \\ P.O. Box 60400, S-10401 Stockholm, Sweden and \\ Leipzig University ${ }^{3}$, Section of Biosciences, \\ Department of Histochemistry, Talstr. 33, \\ O-7010 Leipzig, FRG.
}

Received for publication March 16, 1990 and in revised form June 30, 1990

\begin{abstract}
Comparing galanin and GAD immunoreactive axons in the rostral part of the basal forebrain complex, striking differences were observed regarding their distribution patterns and axonal morphology. In regions with very dense GABAergic innervation, galanin positive fibres were absent. The functional significance of these differences is not yet known. "Stalked" boutons were only formed by galanin containing axons, contrary to GABAergic axons which were endowed with boutons "en passage", only. In galanin immunoreactive sections counterstained with cresylviolet most of boutons were found to be distributed in the neuropil.
\end{abstract}

Galanin is supposed to be a neuropeptide influencing the release of acetylcholine from axon terminals or inhibiting the activity of cholinergic projection neurons by galanin containing interneurons $(4,6,11)$. In the rat basal forebrain $(\mathrm{BF})$, galanin was found to be colocalized in a subpopulation of cholinergic neurons located in the medial septal and diagonal band regions (12). The efferent projection of these double-labelled cholinergic neurons has been elucidated by use of fluorecent tracer injection in the hippocampal region, leading to their identification as galanin containing cholinergic septo-hippocampal projection neurons (129).

Contrary to the galanin containing neurons of the septal region, galanin reactive fibres were found to be immunolabelled also in rat brains which were untreated with colchicine. Their distribution pattern is not congruent with that of galanin immunostained cells but seems to be correlated with some cytoarchitectonically and im-

Address reprint requests to: Andreas Schober, University Leipzig, Section of Biosciences, Department of Histochemistry, Talstr. 33, O-7010 Leipzig, FRG. 
munocytochemically defined subregions of the medial septal and diagonal band nuclei $(9,18)$ and differs remarkably from that of glutamic acid decarboxylase (GAD) or gamma-amino butyric acid (GABA) immunostained fibres. As GABA and galanin are known to influence the activity of contacted cholinergic neurons by inhibition or selfregulation $(4,6,13)$, the comparison of their distribution patterns may give rise to some implications regarding the output regulation of the BF nuclear complex.

\section{MATERIALS AND METHODS}

\section{Galanin and AChE Immunohistochemistry}

Four adult male Wistar rats were anaesthetized with diethyl ether (two animals were given an injection of colchicine- $120 \mu \mathrm{g} / \mathrm{rat}$ in $20 \mu \mathrm{l}$ saline) by transcardial perfusion of isotonic saline $(0.9 \%)$ followed by a fixative, containing $4 \%$ paraformaldehyde in $0.1 \mathrm{M}$ phosphate buffer $(\mathrm{PB}), \mathrm{pH} 7.4$. After $15 \mathrm{~min}$ of perfusion, the brains were removed and the forebrains were dissected out. The tissue blocks were postfixed in the same solution at $4^{\circ} \mathrm{C}$ for $12 \mathrm{hr}$ followed by another $12 \mathrm{hr}$ in $\mathrm{PB}$, containing $20 \%$. sucrose at $4^{\circ} \mathrm{C}$. Frontal sections $(50 \mu \mathrm{m})$ cut on a Vibratome (Oxford Lab., USA) were rinsed for $12 \mathrm{hr}$ in $\mathrm{PB}$ (containing $0.2 \%$ Triton $\mathrm{X}-100$ ) at $4^{\circ} \mathrm{C}$. Alternate sections were stained using NADPH-diaphorase histochemistry according to SchererSingler et al. (15) and were counterstained using cresylviolet. The galanin immunohistochemistry with a polyclonal rabbit anti-galanin antiserum (Peninsula Labs., USA), the acetylcholinesterase (AChE) immunohistochemistry with a polyclonal rabbit anti-AChE antiserum (Dr. Grassi, Gif-sur-Yvette, France). The following sequential procedure (19) was carried out in: 1) normal goat serum (1:50, $60 \mathrm{~min}$, room temperature); 2) antiserum to galanin (1:1000) or antiserum to AChE $(1: 1000)$ for $36 \mathrm{hr}$ at $\left.4{ }^{\circ} \mathrm{C} ; 3\right)$ goat anti-rabbit immunoglobulin $(1: 30,1 \mathrm{hr}$, , room temperature) and 4) rabbit peroxidase-antiperoxidase (PAP) complex $(1: 500,2 \mathrm{hr}$, room temperature). After each incubation step, the sections were rinsed three times (10 $\mathrm{min})$ in $\mathrm{PB}$. All solutions with exception of diaminobenzidine (DAB) solution contained $0.2 \%$ Triton $\mathrm{X}-100$. After $\mathrm{DAB}-\mathrm{H}_{2} \mathrm{O}_{2}$ reaction, the tissue slices were mounted on glass slides, dehydrated and mounted in neutral balsam. In controls, the first antibodies were replaced by normal rabbit serum or omitted.

\section{GAD Immunohistochemistry}

Two adult male Wistar rats were perfused in diethyl ether anaesthesia with $50 \mathrm{ml}$ $0.9 \% \mathrm{NaCl}$ followed by a fixative containing $5 \%$ paraformaldehyde, $0.9 \% \mathrm{NaCl}$, $0.5 \%$ zinc salicylate in distilled water. The removed brains were postfixed for $2-3 \mathrm{hr}$ in the same fixative at $4^{\circ} \mathrm{C}$ and rinsed overnight in $0.1 \mathrm{M}$ Tris-buffered saline (TBS), $\mathrm{pH}$ 7.4. The forebrains were transversally cut with a Vibratome $(50 \mu \mathrm{m})$. The sections were again rinsed in several changes of TBS. The GAD immunohistochemistry was performed with the polyclonal S3 GAD antiserum (14). The free-floating sections were stained by the following procedure: 1) $3 \% \mathrm{H}_{2} \mathrm{O}_{2}$ in $10 \%$ methanol, $10 \mathrm{~min}$; $0.5 \%$ Triton $\mathrm{X}-100,10 \mathrm{~min} ; 3)$ preincubation with $10 \%$ normal rabbit serum and $0.1 \mathrm{M}$ D-L-lysin for $12 \mathrm{hr}$; 4) S3 GAD antiserum (from sheep), $1: 2000 \mathrm{for} 24 \mathrm{hr} ; 5$ ) rabbit anti-sheep and goat immunoglobulins, $1: 50$ for $45 \mathrm{~min}$; 6) peroxidase-antiperoxidase complex (PAP, from goat), $1: 200$ for $45 \mathrm{~min}$. DAB was used as chromogen after intensification procedure according to Adams (1). All incubation steps were carried out at room temperature and the sections were rinsed in several 
changes of TBS. Finally, the sections were mounted on glass slides with alcoholic gelatine. Specificity controls were carried out by omitting the primary antibody.

\section{RESULTS}

\section{Galanin}

Contrary to the cell bodies, the galanin containing axons were immunostained as well in colchicine treated as in untreated rat brains. Compared with the neighbouring nuclei of the lateral septum, the septal nucleus was poorly innervated by galanin containing fibres (Fig. 1a). They were absent inside the vertical (vDB) and horizontal (hDB) limb of the diagonal band, only the marginal and lateral border zones were innervated. A broad and very dense band of galanin containing fibres occupied the lateral border line of the $\mathrm{hDB}$ and its ventro-lateral extension, forming here an arrowhead-like figure in transversal sections (Fig. 1a). This band of fibres converged with another band of galanin positive fibres which were located medially to the nc. accumbens. This lateral fibre assembly could be followed up for caudal levels in serial sections. It was found to be distributed in the ventral pallidum (VP), but also in the subtantia innominata-nc. basalis Meynert complex (SI-NB). In the latter one they showed their highest packing density in the ventral part beneath the zone surrounding the globus pallidus. Like in the $\mathrm{hDB}$, the galanin containing fibres were absent in the nc. preopticus magnocellularis (NPM).

The stained axons represented terminal branchings rich in varicosities. These varicosities represented two types: one could be found in the course of the axon, the other one was situated at the tip of short stalks originating from the irregularly twisted axonal main shafts (Figs. 2a, b). These two types of varicosities occurred in the same axons. Most of the axons gave rise to short side-branches which likewise formed the "stalked" varicosities.

Two series were counterstained with cresylviolet to look for possible correlations between Nissl-stained cell bodies and the galanin immunoreactive fibres. These double stainings showed that the varicosities of galanin positive fibres seem to be randomly distributed in the neuropil. No preference for their location at the surface of neuronal somata could be registered (Fig. 1c).

One brain was stained for galanin and AChE immunohistochemistry in alternate transversal sections through the BF region. It could be seen that the most dense innervation with galanin positive fibres was found in regions of the $\mathrm{BF}$ nuclei where several AChE positive cell assemblies formed insular conglomerates. Such regions were the lateral border of the $\mathrm{hDB}$, the ventral part of the bed nucleus of stria terminalis and the center of the ventral part of SI-NB.

$G A D$

Contrary to the distribution patterns of galanin containing axons, all $\mathrm{BF}$ regions were supplied with GAD containing fibres, but in different densities. The highest density of GAD positive axons in the BF was found in some regions where galanin

FIGs. 1a-c. a. Distribution patterns of galanin positive fibres in the septum and ventral pallidum.

b. Distribution patterns of GAD positive fibres in the septum and ventral pallidum.

c. Galanin immunoreactivity counterstained with Nissl technique. Cell somata are not surrounded by axonal varicosities. 


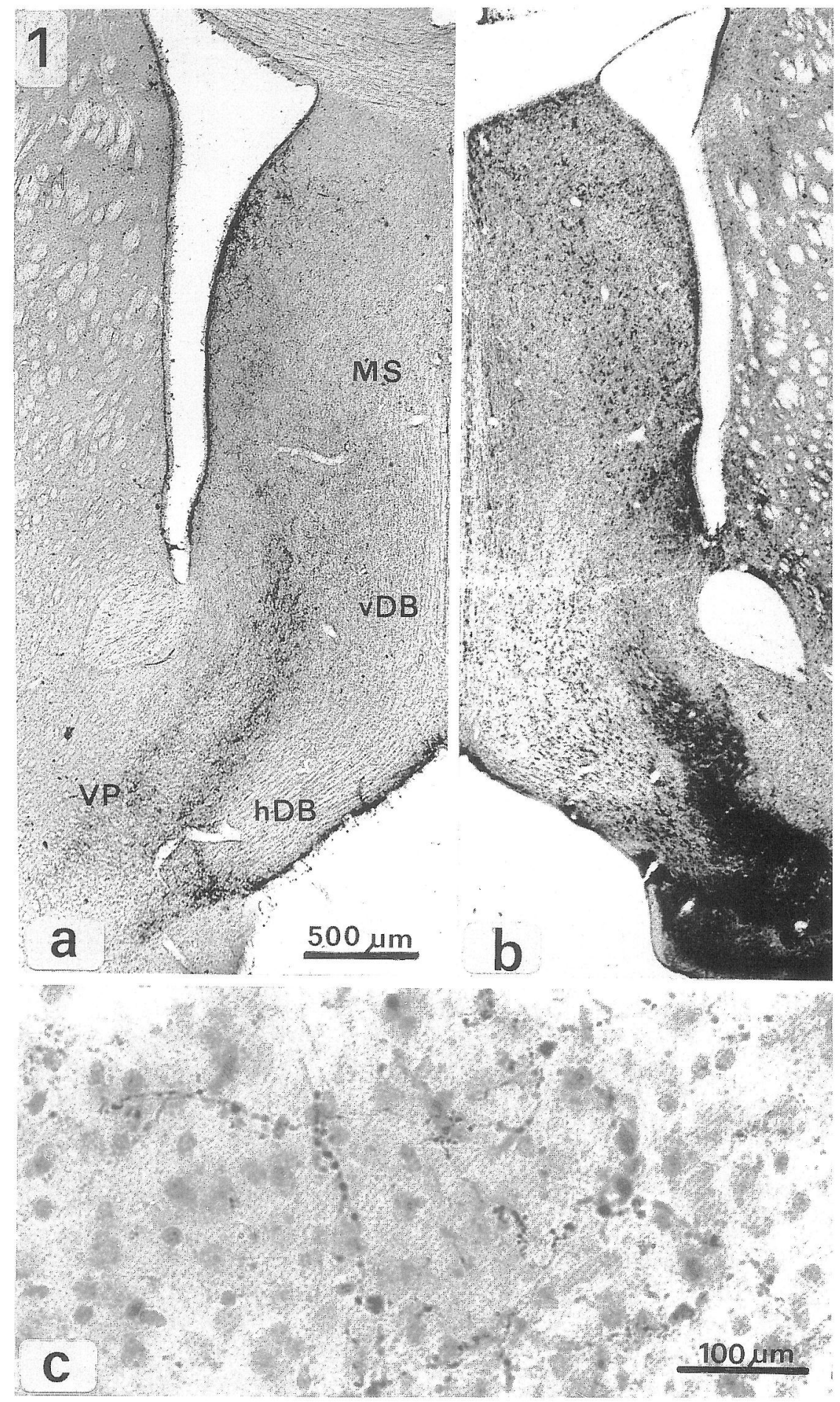




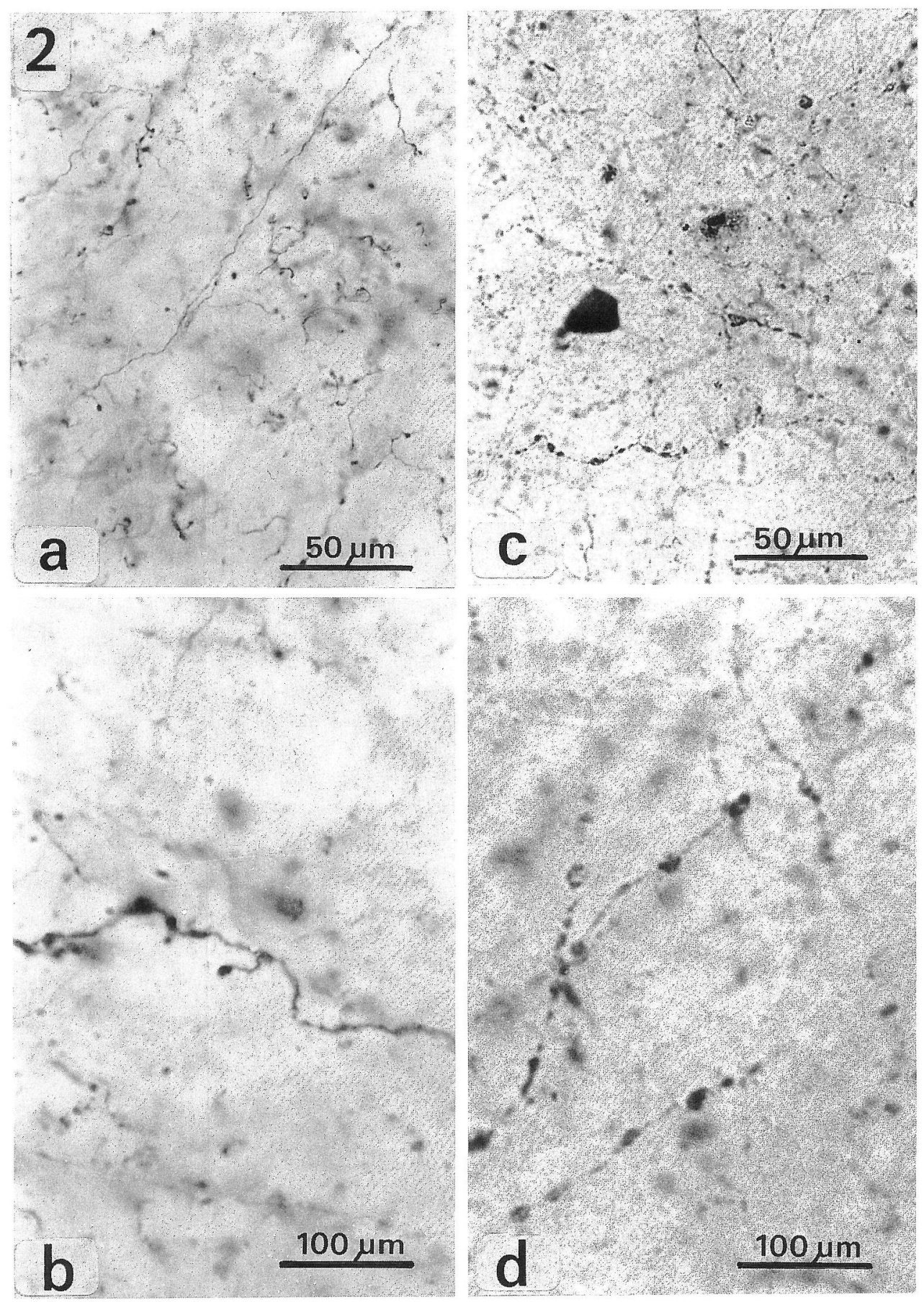

FIGS. 2a-b. Galanin positive fibres, in Fig. b "stalked" varicosities are well visible. $c, d$. GAD positive fibres, in $d$. varicosities of the "en passage" type can be seen. 
reactive fibres were absent, i.e. the VP and the dorsal part of the SI-NB (Fig. 1b).

The morphology of GAD positive axons differed remarkably from that of galanin containing fibres. The axons appeared also poorly branched but the varicosities were larger and only of the "en passage" type. No "stalked" varicosities were present contrary to galanin positive fibres (Figs. 2c, d). In serial sections of colchicine treated brains, where galanin immunohistochemistry was combined with NADPHdiaphorase histochemistry, no double-labelling was obtained.

\section{DISCUSSION}

The fibres expressing galanin immunohistochemistry in the rat BF complex represent a type of axon which has been frequently found in telencephalic and diencephalic regions $(5,8)$. The characteristic feature of this morphologically determined type consists of very short side branches, known as stalked boutons, which are characteristic of cortical axons distributed in the dorsal lateral geniculate nucleus, for instance $(3,5)$. In this diencephalic region this morphological type of axon was found to contact the distal portions of dendries (7).

In the rat BF complex a similar type, resembling the galanin positive fibres of this region, was also stained in Golgi-Kopsch series besides other axonal types (17). In our preparations, where the galanin immunoreactivity was combined with Nissl-staining, no signs of a preferential axo-somatic connectivity have been found, giving rise to the conclusion that they mainly contact the neuropil also in this region, i.e. dendrites.

The origin of the galanin immunostained axons in the rat BF is not yet knwon, as is not the possible content of other neuroactive substances which may come into question (10). This has to be further investigated by using immunohistochemistry. As numerous boutons, which apparently are peptidergic, were found at the electron microscopic level (2), it can be assumed that galanin containing terminals may form a part of them. The distribution patterns of galanin positive axons are of some interest, especially when compared with the distribution patterns of GAD immunoreactive axons (Brauer et al., in preparation).

The high density of axons in regions where some assembles of cholinergic cells occur, implies the assumption that special functional interrelations between these two neuronal components exist which have to be elucidated. One of these cholinergic subpopulations in the rostral $\mathrm{BF}$ is the outer assembly of cholinergic cells near the margin between hDB and VP. These cells have never shown coexpression of NADPHdiaphorase histochemistry (16), contrary to other cholinergic subpopulations where double-labelling occurs. It cannot be excluded that not yet known functional interrelations with regard to these findings and the specificity of galanin containing fibre innervation may exist. There is still a lack of information on possible functional differences between these subpopulations of cholinergic neurons. From our investigation, we know that the cholinergic neurons which contain NADPH-diaphorase do not appear identical with those coexpressing galanin immunoreactivity.

Comparing the distribution patterns of galanin and GAD immunoreactive fibres it seems to be obvious that there exist striking differences, which appear opposite in the septal and diagonal band region. Areas which are occupied by especially dense GAD innervation lack the supply of galanin immunoreactive axons. The functional consequences of this observation have to be elucidated. Whereas the action of 
GABAergic axons-represented by GAD positive fibres-on neurons is known to be inhibitory, the function of the galanin positive terminals, as described here, is unknown partly because of the information lacking regarding a possible coexisting neuroactive substance, which seems not to be acetylcholine.

\section{ACKNOWLEDGMENTS}

The authors thank Mrs. B. Bär and Miss M. Volkmann for their excellent technical assistance. This study was supported by a grant of the Ministry of Science and Technology of the GDR.

\section{REFERENCES}

1. Adams, J. C.: Heavy metal intensification of DAB-based HRP reaction product. J. Histochem. Cytochem. 29; 775, 1981.

2. Brauer, K., Hajdu, F., Tömböl, T. and Winkelmann, E.: Ultrastructure of neurons and their synaptic contacts in the medial septal nucleus of the rat. J. Hirnforsch. 31; 123-132, 1990.

3. Brauer, K., Winkelmann, E., Marx, I. und David, H.: Licht- und elektronenmikroskopische Untersuchungen an Axonen und Dendriten in der Pars dorsalis des Corpus geniculatum laterale (Cgld) der Albinoratte. Z. mikrosk.-anat. Forsch. 88; 596-626, 1974.

4. Chan Palay, V.: Galanin hyperinnervates surviving neurons of human basal nucleus of Meynert in dementias of Alzheimer's and Parkinson's disease: A hypothesis for the role of galanin in accentuating cholinergic dysfunction in dementia. J. comp. Neurol. 273; 453-477, 1988.

5. Guillery, R. W.: A study of Golgi preparations from the dorsal lateral geniculate nucleus of the adult cat. J. comp. Neurol. 128; 21-50, 1966.

6. Hökfelt, T., Millhorn, D., Seroogy, K., Tsuruo, Y., Ceccatelli, S., Lindh, B., Meister, B., Melander, T., Schalling, M., Bartfai, T. and Terenius, L.: Coexistence of peptides with classical neurotransmitters. Experientia 43; 768-780, 1987.

7. Lieberman, A. R. and Webster, K. E.: Aspects of synaptic organization of intrinsic neurons in the dorsal lateral geniculate nucleus. J. Neurocytol. 3; 677-710, 1974.

8. Lund, J. S.: Spiny stellate neurons. In Cerebral Cotex, ed. by A. Peters, and E. G. Jones, vol. 1, Plenum Press New York and London, 1984, pp. 255-308.

9. Melander, T., Hökfelt, T. and Rökaeus, A.: Distribution of galanin like immunoreactivity in the rat central nervous system. J. comp. Neurol. 248; 475-517, 1986.

10. Melander, T., Hökfelt, T., Rökaeus, A. and Cuello, A. C., Oertel, W. H., Verhofstad, A. and Goldstein, M.: Coexistence of galanin-like immunoreactivity with catecholamines, 5-hydroxytryptamine, GABA and neuropeptides in the rat CNS. J. Neurosci. 6; 3640-3654, 1987.

11. Melander, T. and Staines, W. A.: A galanin-like peptide coexists in putative cholinergic somata of the septum-basal forebrain complex and in acetylcholinesterase-containing fibres and varicosities within the hippocampus in the owl monkey (Aotus trivergatus). Neurosci. Lett. 68; 17-22, 1986.

12. Melander, T., Staines, W. A., Hökfelt, T., Rökaeus, A., Eckenstein, F., Salvaterra, P. M. and Wainer, B. H.: Galanin-like immunoreactivity in cholinergic neurons of the septum-basal forebrain complex projecting to the hippocampus of the rat. Brain Res. 360; 130-138, 1985.

13. Nordström, Ö., Melander, T., Hökfelt, T., Bartfai, T. and Goldstein, M.: Evidence for an inhibitory effect of the peptide galanin on dopamine release from the rat median eminence. Neurosci. Lett. 73; 21-26, 1987.

14. Oertel, W. H., Schmechel, D. E., Tappaz, M. L. and Kopin, I. J.: Production of a specific antiserum to rat brain glutamic acid decarboxylase by injection of an antigen-antibody complex. Neurosci. 6; 2689-2700, 1986. 
15. Scherer-Singler, U., Vincent, S. R., Kimura, H. and McGeer, E. G.: Demonstration of a unique population of neurons with NADPH-diaphorase histochemistry. J. Neurosci. Meth. 9; 229234, 1983.

16. Schober, A., Brauer, K. and Luppa, H.: Alternate coexistence of NADPH-diaphorase with choline acetyltransferase or somatostatin in the rat neostriatum and basal forebrain. Acta histochem. cytochem. 22; 669-674, 1989.

17. Seeger, G., Brauer, K., und Seeger, J.: Zur ultrastrukturellen Charakteristik von Neuronen des Nc. medialis septi. J. Hirnforsch. in press.

18. Skofitsch, G. and Jacobowitz, D. M.: Immunohistochemical mapping of galanin-like neurons in the rat central nervous system. Peptides 6; 509-546, 1985.

19. Sternberger, L. A.: Immunohistochemistry, Second edition. New York, John Wiley \& Sons, 1979. 